\title{
Review: corneal endothelial cell derivation methods from ES/iPS cells
}

\author{
Shin Hatou ${ }^{*}$ (I) and Shigeto Shimmura
}

\begin{abstract}
Globally, approximately 12.7 million people are awaiting a transplantation, while only 185,000 cases of corneal transplantation are performed in a year. Corneal endothelial dysfunction (bullous keratopathy) due to Fuchs' corneal endothelial dystrophy, or insults associated with intraocular surgeries, shared half of all indications for corneal transplantation. Regenerative therapy for corneal endothelium independent of eye bank eyes has great importance to solve the large supply-demand mismatching in corneal transplantation and reduce the number of worldwide corneal blindness. If corneal endothelial cells could be derived from ES or iPS cells, these stem cells would be the ideal cell source for cell therapy treatment of bullous keratopathy. Four representative corneal endothelial cell derivation methods were reviewed. Components in earlier methods included lens epithelial cell-conditioned medium or fetal bovine serum, but the methods have been improved and materials have been chemically more defined over the years. Conditioned medium or serum is replaced to recombinant proteins and small molecule compounds. These improvements enabled to open the corneal endothelial developmental mechanisms, in which epithelial-mesenchymal and mesenchymal-endothelial transition by TGF beta, BMP, and Wnt signaling have important roles. The protocols are gradually approaching clinical application; however, proof of efficacy and safety of the cells by adequate animal models are the challenges for the future.
\end{abstract}

Keywords: Embryonic stem cells, Induced pluripotent stem cells, Neural crest cells, Epithelial-mesenchymal transition, Transforming growth factor beta, Bone morphogenetic protein, Wnt

\section{Background}

From the data of the Global Survey of Corneal Transplantation and Eye Banking collected between August 2012 and August 2013, approximately 12.7 million people were awaiting transplantation in 134 countries, covering $91 \%$ of the world's population [1]. On the other hand, only 185,000 corneal transplantation were performed in 116 countries [1]. Bullous keratopathy, i.e., corneal endothelial dysfunction due to Fuchs' corneal endothelial dystrophy or insults associated with intraocular surgeries, shared half of all indications for corneal transplantation [1]. Regenerative therapy for corneal endothelium independent of eye bank eyes may help solve the large supply-demand mismatching in corneal transplantation and reduce the number of worldwide corneal blindness.

\footnotetext{
* Correspondence: tr97469@zc4.so-net.ne.jp

Department of Ophthalmology, Keio University School of Medicine, 35 Shinanomchi, Shinjuku-ku, Tokyo, Japan
}

The corneal endothelium consists of a single layer of hexagonal cells with a basement membrane (Descemet's membrane) covering the posterior surface of the cornea in a well-arranged mosaic pattern [2,3]. Corneal hydration is determined primarily by the balance between the movement of aqueous humor across the corneal endothelium into the stroma and the subsequent pumping of the fluid out from the stroma $[2,3]$. The accumulation of fluid in the stroma due to disturbance of this balance may lead to bullous keratopathy, which is characterized by an edematous cornea with a reduced transparency. Tight junction between endothelial cells regulates the movement of aqueous humor across the corneal endothelium into the stroma (barrier function), and the $\mathrm{Na}^{+}-$and $\mathrm{K}^{+}$-dependent ATPase (Na, K-ATPase) expressed in the basolateral membrane of corneal endothelial cells is primarily responsible for the pump function of the corneal endothelium [2]. Given that human corneal endothelial cells (HCEC) have a limited proliferative capacity, Fuchs' corneal endothelial dystrophy and insults associated with intraocular

(c) The Author(s). 2019 Open Access This article is distributed under the terms of the Creative Commons Attribution 4.0 International License (http://creativecommons.org/licenses/by/4.0/), which permits unrestricted use, distribution, and 
surgeries result in corneal endothelial cell loss and permanent damage. Allogenic penetrating keratoplasty (PKP) has been performed for a century, and its low rejection rate is due to anterior chamber-associated immune deviation. Several new corneal endothelial keratoplasty techniques, such as Descemet's membrane stripping automated endothelial keratoplasty (DSAEK) or Descemet's membrane endothelial keratoplasty (DMEK), have been clinically performed. Although these techniques are less invasive than PKP, there still remain some problems, such as acute glaucoma attack due to air bubbles in anterior chamber, or host-graft adhesion failure. Long-term endothelial cell loss of the graft requires re-graft operation with another eye bank eye.

Recently, techniques for in vitro culture of HCEC have improved, and a cell injection therapy into the anterior chamber for bullous keratopathy using cultured corneal endothelial cells and Rho-associated kinase (ROCK) inhibitor has been reported [4]. This was the first proof of concept to treat bullous keratopathy by cell suspension therapy. However, the quality of cultured endothelial cells is largely dependent on donor age, so other cell sources which are totally independent from donor cornea is more desirable. On the other hand, several methods to make corneal endothelial cells from embryonal stem cells (ES cells) or induced pluripotent stem cells (iPS cells) have been reported recently. If possible, ES or iPS cells would be the ideal cell source for cell therapy treatment of bullous keratopathy. In this report, represented methods from these articles are reviewed, and future challenges are discussed.

\section{Development of corneal endothelium}

The anterior segment of the eye is organized from diverse embryological origins, and its mechanism is complicated (Fig. 1). Corneal endothelium and stroma are derived from periocular mesenchyme (POM), or in other words, periocular neural crest cells (NCCs), while corneal epithelium and lens are derived from surface epidermal ectoderm [5]. The cornea is formed at 5-6 weeks of human gestation, when surface ectoderm and lens are completely separated [5]. Mesenchyme cells from neural crest migrate into the space between them and forms several layers [5]. Surface ectoderm becomes corneal epithelium, and the most inner layer mesenchyme becomes corneal endothelium [5]. Next, mesenchyme between corneal epithelium and endothelium becomes the corneal stroma [5]. The endothelial cells become flattened and tightly connected to each other by tight junctions and produce basement membrane which separate endothelium from stroma, called Descemet's membrane [5]. Finally, corneal endothelial cells form typical hexagonal monolayer, and they stay arrested in the G1phase of mitosis $[5,6]$.
The mechanisms of neural crest cell migration and corneal endothelial cell maturation are not fully understood. Neural crest cell migration from neural plate border begins with epithelial-mesenchymal transition (EM-T). They migrate to periocular lesion and subsequently reach the area beneath the corneal epithelium. Transforming growth factor beta (TGF beta) signaling or Wnt signaling may contribute in this process $[7,8]$. However, corneal endothelial cells forms typical endothelial morphology with cobble stone appearance, so there may be reversal steps of mesenchymal-endothelial transition (ME-T) in corneal endothelium maturing process. Some of the transcription factors involved in these events are reported: Foxc1, Foxc2, Lmx1b, Pax6, Pitx2, RAR $\beta$, RAR $\gamma, \operatorname{RXR} \alpha$, Six3, and Smad2 [5, 8-12]. However, it has not been clarified which of them works in migration process or which works during the maturing process. Among them, Foxc1, Pitx2, and Pax6 are responsive genes for anterior segment dysgenesis, Peters' anomaly and Axenfeld-Rieger syndrome [12]. These facts may suggest these transcriptional factors may play a role in migration process.

\section{Strategies for producing corneal endothelial cells from stem cells}

To date, most approaches for producing corneal endothelial cells from ES or iPS cells in vitro were by mimicking developmental process; in the first step, neural crest cells were derived from iPS/ES cells. Next, corneal endothelial cells were derived from neural crest cells. However, the materials and methods vary much with researchers and developers. Four representative methods are reviewed as follows.

\section{Co-culture with corneal stroma cells and lens epithelial cell- conditioned medium}

Since corneal endothelium is located between corneal stroma and lens and it is organized after lens development, corneal endothelial cells may be produced under the influence of lens epithelial cells and corneal stroma cells. Zhang et al. derived corneal endothelial-like cell from human ES cells by co-culture with human corneal stroma cells and lens epithelial cell-conditioned medium (LECCM) [13]. Table 1 shows the summary of their methods. First, embryoid bodies (EB) were formed in low attachment culture dishes. Next, EB were plated on fibronectin, laminin, and heparin sulfate-coated glass coverslips, and co-cultured with corneal stroma cells which were obtained from Chinese eye bank. Co-culture was started with basal medium containing epidermal growth factor (EGF), basic fibroblast growth factor (bFGF), and fetal bovine serum, and subsequently, the medium was changed to LECCM. LECCM were collected from SV-40transformed human lens epithelial cell culture medium. 
Table 1 The summary of Zhang's methods (2014). FM fibroblast differentiation medium, EM corneal endothelial cell differentiation medium, KSR knockout serum replacement, FBS fetal bovine serum, B27 B27 supplement, EB embryoid body

\begin{tabular}{llll}
\hline Steps & EB culture & $\rightarrow$ & Co-culture with corneal stroma cells \\
Medium & DMEM/F12, 20\% KSR, bFGF (8 ng/ml) & FM: DMEM/F12, B27, EGF (20 ng/ml), bFGF (40 ng/ml), 10\% & EM: FM + LECCM (FM:LECCM = 3: \\
& etc. & FBS & $1)$ \\
Coating & Low adherence culture dish & Fibronectin, laminin, heparin sulfate-coated dish & 2 weeks \\
Duration & 7 days & 5 days & 2 ins \\
\hline
\end{tabular}

After 5 days of co-culture, CD73/FoxC1 co-expressing POM cells emigrated from EB. N-cadherin/vimentin dual positive corneal endothelial-like cells were obtained after LECCM culture. Na,K-ATPase alpha-1 and beta-1 subunits were upregulated in their corneal endothelial-like cells. Although precise factors and mechanisms should be further evaluated, these results suggest that some factors from lens epithelial cells and corneal stroma cells may affect corneal endothelial cell development.

\section{All-trans retinoic acid and LECCM}

Chen et al. derived corneal endothelial-like cells from mouse ES cells and mouse iPS cells by all-trans retinoic acid and LECCM [14]. Table 2 shows the summary of their methods. LECCM was obtained from rabbit lens epithelial cell culture medium. EB culture with $1 \mu \mathrm{M}$ all-trans retinoic acid promotes neural crest cell differentiation with high expression of NCCs' markers (Slug, Sox10, p75, etc.). At the second stage differentiation, LECCM derived corneal endothelial-like cells from NCCs. Their corneal endothelial-like cells express $\mathrm{Na}$, K-ATPase, ZO-1, N-cadheirn, Aquaporine-1, etc. Similar to Zhang's method, LECCM has an important role in the final step of corneal endothelial cell derivation as well, and retinoic acid may have some effect, especially on early stage of corneal endothelial development.

\section{Dual Smad inhibition and Wnt inhibition}

The corneal endothelium derivation method by McCabe et al. was a two-step generation procedure but chemically more defined than previous methods [15]. Since TGF beta, bone morphogenetic protein (BMP), and Wnt are related to EM-T process, regulation of these signals may be important for ME-T process in corneal endothelial development. Table 3 shows the summary of their methods. NCCs were derived from ES cells at the first step with TGF beta signaling blocker (SB431542) and Noggin. Both TGF beta-Smad-2/3 signaling and BMPSmad-1/5/8 signaling were blocked, and therefore, the procedure was called "dual Smad inhibition" [16]. NCCs with NGFR, SOX10, and FOXC1 expression could be derived from ES cells by chemically defined condition. Next, platelet-derived growth factor B (PDGF-BB), Dickkopf-related protein 2 (DKK-2), and bFGF were able to generate hexagonal corneal endothelial-like cells. DKK-2 is an antagonist of Wnt/beta-catenin signaling. Their corneal endothelial-like cells express $\mathrm{Na}, \mathrm{K}$-ATPase, ZO1 , and type VIII collagen (COL8A1), which is the component of Descemet's membrane. DNA microarray analysis revealed a close similarity between their corneal endothelial cells and primary cultured human corneal endothelial cells. In addition, Wagoner et al. were able to derive corneal endothelial-like cells from iPS cells by modified McCabe's protocol [17].

\section{Dual Smad inhibition, Wnt inhibition/activation, and ROCK inhibition}

Zhao and Afshari also derived corneal endothelial-like cell from iPS cells under chemically defined conditions (Table 4) [18]. The method contains three steps; dual Smad inhibition with SB431542 and LDN193189 (BMP signaling blocker) and Wnt inhibition by IWP2 promote eye field stem cell development from iPS cells. These eye field stem cells express eye field transcription factors PAX6, LHX2, RAX, SIX3, and SIX6. Next, NCCs with HNK-1 and p75NTR expression could be developed from eye field stem cells by canonical Wnt signaling activator CHIR99021. At the last step, SB431542 and ROCK inhibitor $\mathrm{H}-1125$ were able to derive corneal endothelial-like cells from NCCs. Their corneal endothelial-like cell expressed Na,K-ATPase, ZO-1, and N-cadherin. The characteristics of their procedure is tracing complicated

Table 2 The summary of Chen's methods (2015). IMDM; Iscove's modified Dulbecco's medium. N2; N2 supplement

\begin{tabular}{llll}
\hline Steps & EB culture & $\rightarrow$ & LECCM culture \\
Medium & IMDM, 15\% FBS, IMDM, 15\% FBS, all-trans retinoic acid $(1 \mu \mathrm{M})$, & LECCM (DMEM/F12, N2, B27, bFGF (20 ng/ml), ascorbic acid, \\
& etc. $\quad$ etc. & etc.) \\
Coating & Low adherence culture dish & Gelatin-coated dish \\
Duration & 4 days & 7 days & 7 days \\
\hline
\end{tabular}


Table 3 The summary of McCabe's methods (2015)

\begin{tabular}{lll}
\hline Steps & Dual Smad inhibition & Cornea media \\
Medium & DMEM/F12, 20\%KSR, SB431542 (10 mM), NOGGIN (500 ng/ml), bFGF & DMEM/F12, 20\%KSR, PDGF-BB (10 ng/ml), DKK-2 (10 ng/ml), bFGF \\
& $(8 \mathrm{ng} / \mathrm{ml})$ & $(8 \mathrm{ng} / \mathrm{ml})$ \\
Coating & Matrigel-coated well & Matrigel-coated well \\
Duration & 3 days & 14 days \\
\hline
\end{tabular}

EM-T (Wnt activation) and ME-T (Wnt and Smad inhibition) process in corneal endothelial cell development by several small molecule compounds, rather than recombinant proteins. These small molecule compounds may enable reduction of production costs.

\section{Self-formed ectodermal autonomous multi-zone method}

Hayashi et al. demonstrated the generation from human induced pluripotent stem cells of a self-formed ectodermal autonomous multi-zone (SEAM) of ocular cells [19]. SEAM mimics whole-eye development because cell location within different zones is indicative of lineage, spanning the ocular surface ectoderm, lens, neuro-retina, and retinal pigment epithelium [19]. Interestingly, although SOX10+/p75+ neural crest cells were also found to have emerged in satellite spheres [19], the population of corneal endothelial-like cells seemed to be absent in SEAM. Additional trigger may be required for corneal endothelial cell development from neural crest cells in SEAM.

Table 5 summarizes more detail of the reviewed methods, including cell source and strain (ES or iPS cells, mouse or human), quality check, and in vivo transplant methods.

\section{Challenges for the future}

Year by year, the methods have been improved and chemically more defined, which were helpful in not only improving repeatability, but also revealing background mechanisms in corneal endothelium development (Fig. 1). Especially, TGF beta, BMP, or WNT signaling regulation commonly played important roles in the reviewed methods, so EM-T and ME-T process may be the key steps for corneal endothelial cell development. LECCM may include molecules with these effects; however, chemically defined recombinant proteins or small molecule compounds would be more desirable for the purpose of clinical application. Small molecule compounds may also have a merit to reduce product cost.

These improvements may have corneal endothelial regenerative medicine from iPS/ES cells more realistic in the near future. Especially, corneal endothelial regenerative medicine is thought to be very compatible with allogenic iPS/ES cell source, because of anterior chamber-associated immune deviation. Compared to autologous regenerative medicine, allogenic iPS/ES cell source will be able to reduce the cost for cell products.

However, in order to realize regenerative medicine of bullous keratopathy, there are still many problems to be solved. First, there are still no established specific corneal endothelial cell markers, so the markers used vary in each report. $\mathrm{Na}, \mathrm{K}$-ATPase expression as pump function marker and ZO-1 expression as tight junction marker are at least necessary as corneal endothelial cells, and many reports have covered them. However, these two markers are not specific for corneal endothelial cells. Corneal endothelial specific markers which, if possible, link corneal endothelial characteristics or functions would be desired.

Next, some animal origin materials, such as fetal bovine serum and Matrigel, have still been used in these methods. Component information of other materials, such as human endothelial serum-free medium (HESFM) and knockout serum replacement (KSR), are not fully disclosed. The effect of these materials may mask true mechanisms. In addition, the inter-lot difference of animal origin materials may have influenced on products' repeatability. Recently, we have succeeded in corneal endothelial-like cell production by our original methods with totally animal-free, chemically defined materials (unpublished data), which may be more

Table 4 The summary of Zhao's methods (2016)

\begin{tabular}{|c|c|c|c|c|c|}
\hline Steps & Eye field stem cells differentiation & $\rightarrow$ & $\begin{array}{l}\text { Ocular neural crest stem cells } \\
\text { differentiation }\end{array}$ & $\rightarrow$ & Corneal endothelial cell induction \\
\hline Medium & 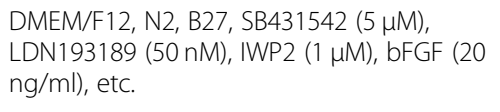 & & $\begin{array}{l}\text { DMEM/F12, N2, B27, CHIR99021 } \\
(3 \mu \mathrm{M}) \text {, 2-phospho-L-ascorbic acid (0.3 } \\
\text { mM), etc. }\end{array}$ & & $\begin{array}{l}\text { HE-SFM, 5\% FBS, SB431542 (1 } \mu \mathrm{M}), \mathrm{H}-1125 \\
(2.5 \mu \mathrm{M}), 2 \text {-phospho-L-ascorbic acid }(0.3 \\
\mathrm{mM}) \text {, etc. }\end{array}$ \\
\hline Coating & Matrigel-coated well & & Matrigel-coated well & & FNC coating mix \\
\hline Duration & 2 days & & $\sim 80 \%$ confluence & & 1 week \\
\hline
\end{tabular}


Table 5 Summary of details of reviewed methods, including cell source and strain (ES or iPS cells, mouse or human), markers for cell sorting, quality check experiments, and in vivo transplant methods

\begin{tabular}{|c|c|c|c|c|}
\hline & $\begin{array}{l}\text { Zhang et al. (2014) } \\
\text { [13] }\end{array}$ & Chen et al. (2015) [14] & McCabe et al. (2015) [15] & Zhao and Afshari (2016) [18] \\
\hline Cell source & Human ES cells & Mouse ES cells and iPS cells & Human ES cells & Human ES cells and iPS cells \\
\hline Sorting & $\begin{array}{l}\text { Vimentin/N-cadherin } \\
\text { double positive cells } \\
(7.68 \%)\end{array}$ & N. A. & N. A. & N. A. \\
\hline $\begin{array}{l}\text { Quality } \\
\text { check }\end{array}$ & $\begin{array}{l}\text { Real-time PCR } \\
\text { (ATP1A1, ATP1B1) }\end{array}$ & $\begin{array}{l}\text { Immunostaining and real-time PCR (Na, K-ATPase, } \\
\text { N-cadherin, ZO-1, Aquaporine-1, Vimentin, VE- } \\
\text { cadherin, etc.) }\end{array}$ & $\begin{array}{l}\text { Real-time PCR (COL8A1, } \\
\text { AQP1), immunostaining (ZO- } \\
\text { 1, ATP1A1) }\end{array}$ & $\begin{array}{l}\text { Real-time PCR (ATP1A1), } \\
\text { immunostaining (ATP1A1, } \\
\text { ZO1, N-cadherin) }\end{array}$ \\
\hline $\begin{array}{l}\text { In vivo } \\
\text { transplant } \\
\text { model }\end{array}$ & $\begin{array}{l}\text { Rabbit, sheet } \\
\text { transplantation }\end{array}$ & N. A. & N. A. & N. A. \\
\hline
\end{tabular}

N. A. not analyzed

suitable for clinical trial compared to previous methods. These cells appear cobblestone morphology and express $\mathrm{Na}, \mathrm{K}$-ATPase alpha-1 subunits, ZO-1, N-cadherin on cell borders, and PITX2 in cell nuclei (Fig. 2). Comparing four reviewed methods, our corneal endothelial-like cells are unique which completed these four corneal endothelial cell markers.

Lastly, adequate animal models to prove corneal endothelial-like cell function and safety are desired. Zhang et al. performed corneal endothelial-like cell sheet transplantation in rabbit eyes. However, clinically applicable scaffold will be necessary for cell sheet transplantation. The difficulty is that such a scaffold itself is required to keep transparency after transplantation. On the other hand, cell injection methods into rabbit eyes have other difficulties since the anterior chamber space of rabbits is very narrow. Kinoshita et al. proved cultured corneal endothelial cell function by cell injection into the monkey bullous keratopathy model eyes [4]. Primate animal model has a merit that the anterior chamber space is wider than rodents; however, such primate animal model requires much higher costs. In addition, not only the proof of cell function, but also the proof of safety by the animal study would be necessary, especially for the products made from ES or iPS cells.

\section{Conclusion}

Representative methods for corneal endothelial-like cell derivation from ES or iPS cells have been reviewed. The components in the methods have been shifted from animal origin materials to recombinant cytokines and small molecule compounds year by year. Although there still

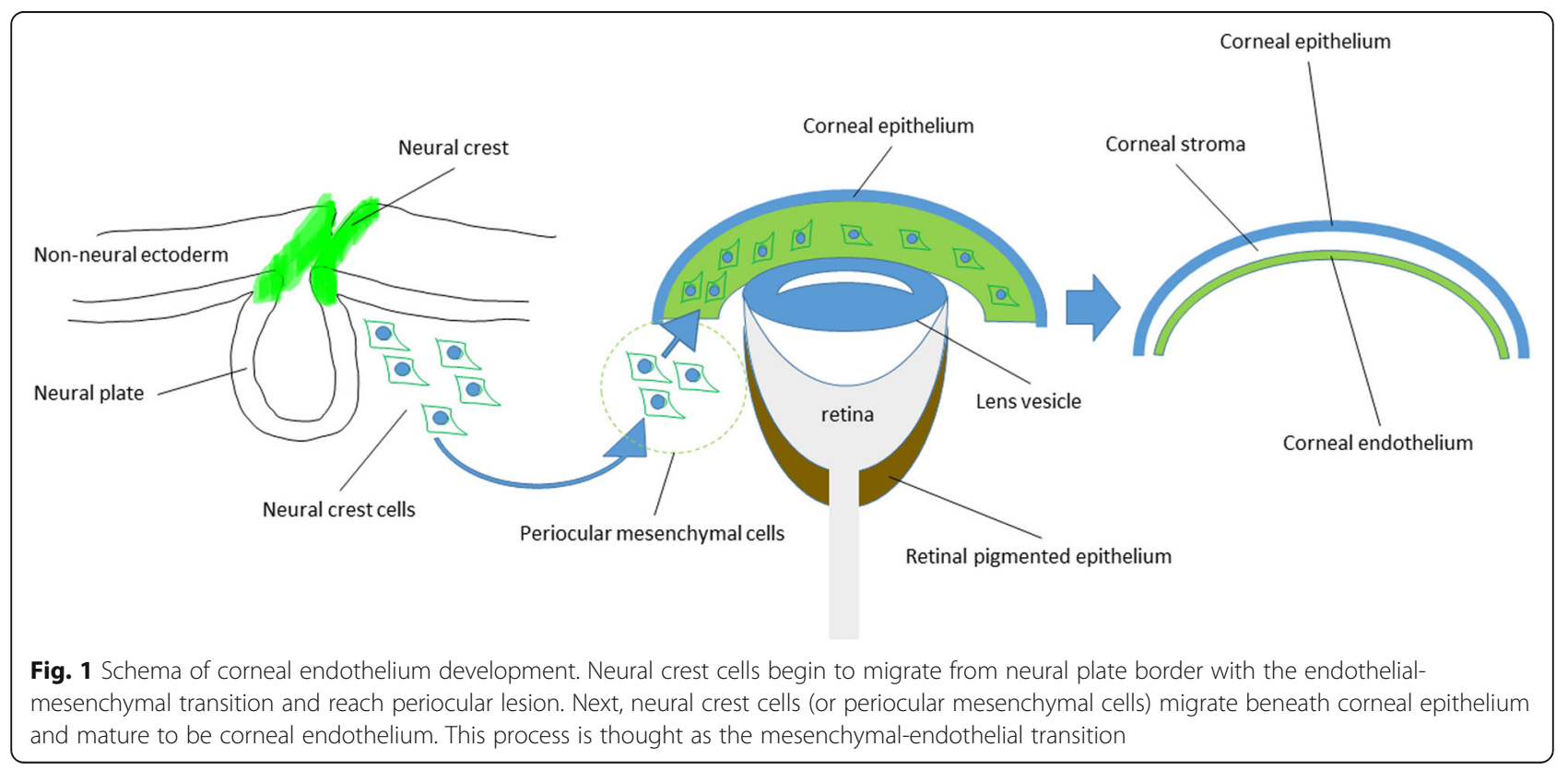




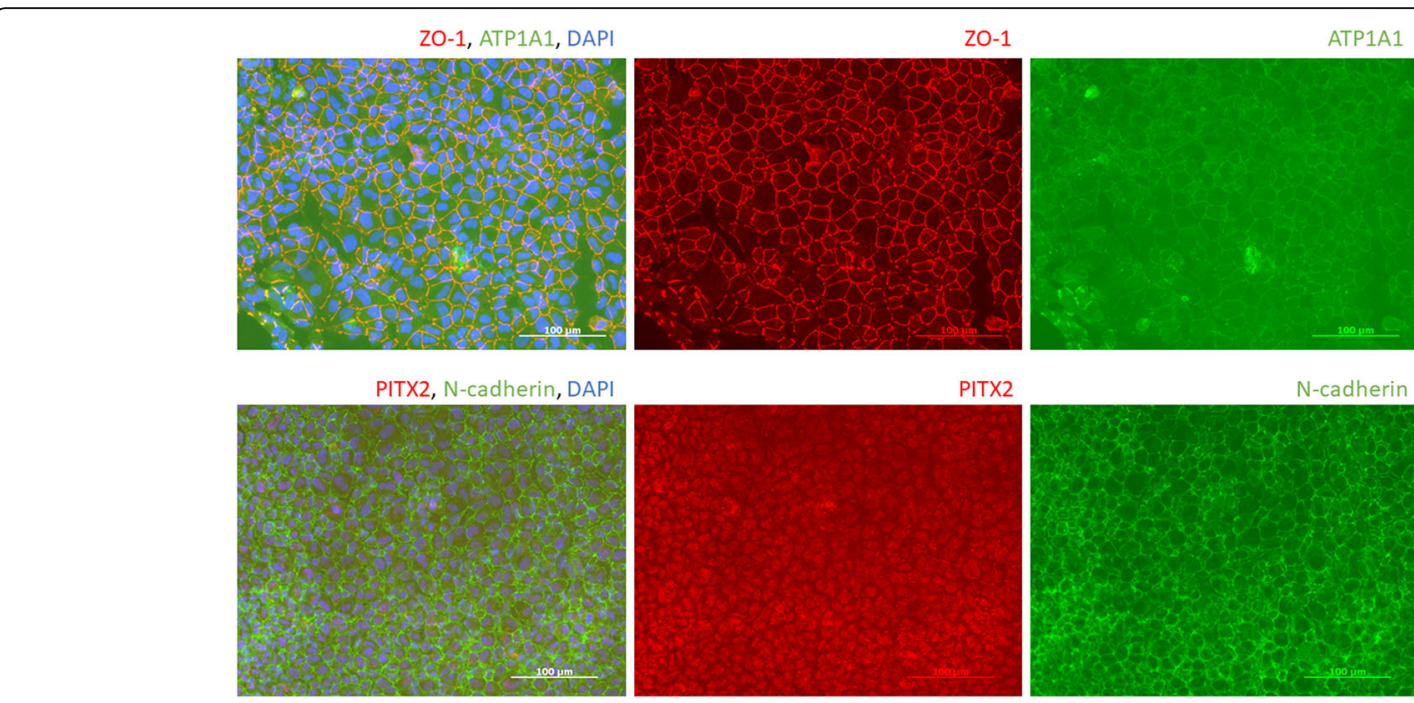

Fig. 2 Corneal endothelial-like cell from our lab. Na,K-ATPase alpha-1 subunit (ATP1A1), ZO-1, and N-cadherin express on the cell border, and PITX2 express on cell nuclei

are unknown mechanisms involved, such improvements may enable to reveal developmental process of corneal endothelial cell more clearly in the near future. Efficacy and safety test with adequate animal models will be the challenge for the future.

\section{Abbreviations \\ bFGF: Basic fibroblast growth factor; DKK-2: Dickkopf-related protein 2; DMEK: Descemet's membrane endothelial keratoplasty; DSAEK: Descemet's membrane stripping automated endothelial keratoplasty; EB: Embryoid bodies; EGF: Epidermal growth factor; EM: Corneal endothelial cell differentiation medium; EM-T: Epithelial-mesenchymal transition; ES cells: Embryonal stem cells; FBS: Fetal bovine serum; FM: Fibroblast differentiation medium; HCEC: Human corneal endothelial cells; HE- SFM: Human endothelial serum-free medium; IMDM: Iscove's modified Dulbecco's medium; iPS cells: Induced pluripotent stem cells; KSR: Knockout serum replacement; LECCM : Lens epithelial cell-conditioned medium; ME- T: Mesenchymal-endothelial transition; NCCs: Neural crest cells; PDGF- BB: Platelet-derived growth factor B; PKP: Penetrating keratoplasty; POM: Periocular mesenchyme; ROCK: Rho-associated kinase; TGF beta: Transforming growth factor beta}

\section{Acknowledgements}

Kazuo Tsubota, Professor of Ophthalmology, Keio University School of Medicine.

\section{Authors' contributions}

SH (corresponding author); SS. All authors read and approved the final manuscript.

\section{Funding}

This research is supported by funding from the Research Project for Practical Applications of Regenerative Medicine of Japan Agency for Medical Research and Development (AMED) and Cellusion Inc.

\section{Availability of data and materials}

Please contact the authors for data requests.

\section{Ethics approval and consent to participate}

Our study with human iPS cells has been approved by the Ethics Committee about human ES, human iPS, and human tissue stem cells in Keio University School of Medicine (reference number: 2018-04).

\section{Consent for publication}

Not applicable

\section{Competing interests}

Shin Hatou received fees from Cellusion, Inc. and is holding stocks in Cellusion, Inc. Shigeto Shimmura received funding from Cellusion, Inc. and is holding stocks in Cellusion, Inc.

Received: 15 April 2019 Accepted: 21 August 2019

Published online: 03 October 2019

\section{References}

1. Gain P, Jullienne R, He Z, Aldossary M, Acquart S, Cognasse F, et al. Global survey of corneal transplantation and eye banking. JAMA Ophthalmol. 2016; 134(2):167-73.

2. Dawson DG, Ubels JL, Edelhauser HF. Cornea and sclera. 11th ed. London: Elsevier Saunders; 2011.

3. Nishida T, Saika S. Cornea and sclera: anatomy and physiology. London: Elsevier Mosby; 2011.

4. Kinoshita S, Koizumi N, Ueno M, Okumura N, Imai K, Tanaka H, et al. Injection of cultured cells with a ROCK inhibitor for bullous keratopathy. N Engl J Med. 2018:378(11):995-1003.

5. Zavala J, Lopez Jaime GR, Rodriguez Barrientos CA, Valdez-Garcia J. Corneal endothelium: developmental strategies for regeneration. Eye (London, England). 2013;27(5):579-88.

6. Joyce NC, Harris DL, Mello DM. Mechanisms of mitotic inhibition in corneal endothelium: contact inhibition and TGF-beta2. Invest Ophthalmol Vis Sci. 2002:43(7):2152-9.

7. Saika S, Saika S, Liu CY, Azhar M, Sanford LP, Doetschman T, et al. TGFbeta2 in corneal morphogenesis during mouse embryonic development. Dev Biol. 2001;240(2):419-32.

8. Zacharias AL, Gage PJ. Canonical Wnt/beta-catenin signaling is required for maintenance but not activation of Pitx2 expression in neural crest during eye development. Dev Dyn : an official publication of the American Association of Anatomists. 2010:239(12):3215-25.

9. Bennett JL, Zeiler SR, Jones KR. Patterned expression of BDNF and NT-3 in the retina and anterior segment of the developing mammalian eye. Invest Ophthalmol Vis Sci. 1999:40(12):2996-3005.

10. Collinson JM, Quinn JC, Hill RE, West JD. The roles of Pax6 in the cornea, retina, and olfactory epithelium of the developing mouse embryo. Dev Biol. 2003;255(2):303-12.

11. Gage PJ, Zacharias AL. Signaling "cross-talk" is integrated by transcription factors in the development of the anterior segment in the eye. Dev Dyn : an official publication of the American Association of Anatomists. 2009; 238(9):2149-62 
12. Ito YA, Walter MA. Genomics and anterior segment dysgenesis: a review Clin Exp Ophthalmol. 2014;42(1):13-24.

13. Zhang K, Pang K, Wu X. Isolation and transplantation of corneal endothelial cell-like cells derived from in-vitro-differentiated human embryonic stem cells. Stem Cells Dev. 2014;23(12):1340-54.

14. Chen P, Chen JZ, Shao CY, Li CY, Zhang YD, Lu WJ, et al. Treatment with retinoic acid and lens epithelial cell-conditioned medium in vitro directed the differentiation of pluripotent stem cells towards corneal endothelial celllike cells. Exp Ther Med. 2015;9(2):351-60.

15. McCabe KL, Kunzevitzky NJ, Chiswell BP, Xia X, Goldberg JL, Lanza R. Efficient generation of human embryonic stem cell-derived corneal endothelial cells by directed differentiation. PLoS One. 2015;10(12): e0145266.

16. Lee G, Chambers SM, Tomishima MJ, Studer L. Derivation of neural crest cells from human pluripotent stem cells. Nat Protoc. 2010:5(4):688-701.

17. Wagoner MD, Bohrer LR, Aldrich BT, Greiner MA, Mullins RF, Worthington $\mathrm{KS}$, et al. Feeder-free differentiation of cells exhibiting characteristics of corneal endothelium from human induced pluripotent stem cells. Biol Open. 2018;7(5):1-10.

18. Zhao JJ, Afshari NA. Generation of human corneal endothelial cells via in vitro ocular lineage restriction of pluripotent stem cells. Invest Ophthalmol Vis Sci. 2016;57(15):6878-84.

19. Hayashi R, Ishikawa Y, Sasamoto Y, Katori R, Nomura N, Ichikawa T, et al. Coordinated ocular development from human iPS cells and recovery of corneal function. Nature. 2016;531(7594):376-80.

\section{Publisher's Note}

Springer Nature remains neutral with regard to jurisdictional claims in published maps and institutional affiliations.

Ready to submit your research? Choose BMC and benefit from:

- fast, convenient online submission

- thorough peer review by experienced researchers in your field

- rapid publication on acceptance

- support for research data, including large and complex data types

- gold Open Access which fosters wider collaboration and increased citations

- maximum visibility for your research: over $100 \mathrm{M}$ website views per year

At $\mathrm{BMC}$, research is always in progress.

Learn more biomedcentral.com/submissions 